\title{
Failure behavior of PA12 based SLS lattice structure with macro-porosity
}

\author{
Serap Gümüs ${ }^{1, *}$, Juergen M. Lackner ${ }^{2}$, Şeyda Polat ${ }^{1}$, Wolfgang Kraschitzer ${ }^{3}$, Hermann \\ Hanning ${ }^{4}$, Alperen Bayram ${ }^{5}$, Mesut Kaya ${ }^{5}$, Metin Çalli ${ }^{5}$, and Attila Alkan ${ }^{1}$ \\ ${ }^{1}$ Kocaeli University, Department of Metallurgical and Materials Engineering, Kocaeli, Turkey \\ ${ }^{2}$ Joanneum Research Forschungsgesellschaft mbH, Leobner Strasse 94, 8712 Niklasdorf, Austria \\ ${ }^{3}$ RPD Rapid Product Development GmbH, Industriestrasse Ost 7, 8605 Kapfenberg, Austria \\ ${ }^{4}$ LSS Laser Sinter Service GmbH, Industriestrasse Ost 7, 8605 Kapfenberg, Austria \\ ${ }^{5}$ Coşkunöz R\&D Center, Organize Sanayi Bölgesi Sarı Cad. No:7, 16140 Bursa / Turkey
}

\begin{abstract}
Nowadays the demands of high reliability, high mechanical properties under fatigue loading and ultra-light-weight design are topics of pressing needs in different industry applications. Additive manufacturing technique has great potential to meet such demands and Selective Laser Sintering (SLS) is the dominantly used one due to its versatility in material design, construction and the much higher achievable mechanical strength compared to its competing technologies like fused filament fabrication. In this study, it is aimed to give an insight to the fracture behaviour of SLS produced lattice structure with macro-porosity under compression load. The stress type and distribution on the lattice structure under compression load are anisotropic because of the unit cell topologies and the anisotropic processing condition. Therefore, different kinds of fracture types are evident depending on the region of the fractured struts.
\end{abstract}

\section{Introduction}

Light-weight and control of elasticity/flexibility are pressing needs in future automotive applications and can be achieved by macro-porosity (lattice structure). Especially in the field of small series production by selective laser sintering (SLS), a highly versatile additive manufacturing (AM) technology, design increasingly uses open-porosity to optimally use the powder based materials and to achieve ultra-low-weight. The need of light-weight design and green manufacturing by minimizing the required material, leads to the goal of studying the influence of internal macro-porosity in a lattice structure produced by SLS.

SLS is the dominantly used technique in AM due to its versatility in material design and construction (integrated functionalized design) and due to the possibility of achieving much higher mechanical strength compared to Fused Deposition Modelling, Polyjet or Lithography technologies [1]. SLS is best applicable to semi-crystalline polymers like the mostly used polyamides (PA12, PA6) [2]. They have a sufficiently large sintering temperature window between the crystallization $\left(\mathrm{T}_{\mathrm{c}}\right)$ and melting temperatures $\left(\mathrm{T}_{\mathrm{m}}\right)$. The

*Corresponding author: sgumus@kocaeli.edu.tr 
powder bed temperature is kept within this operating temperature window during the process for preventing distortion and shrinkage cracks. For sintering and melting, the laser heats only the newly applied powder layer on top, above $\mathrm{T}_{\mathrm{m}}$. During SLS, only a part of the power bed is sintered to the desired component shapes, while the rest in the surrounding stays non-sintered. Nevertheless, powder storage above $T_{c}$ results in aging (increase/decrease of molecular weight), which limits the re-use of powder due to the change in thermal properties. Therefore, the thermal management (accurate sensing and control of local powder bed temperature, laser power and scanning) during SLS processing is decisive.

In this study, fracture mechanisms of lattice structure with macro-porosity are investigated. Microstructural characterization is performed to evaluate the failure behaviour under compression load using scanning electron microscope (SEM).

\section{Experimental}

Two different unit cell topologies are chosen as lattice structures (Figure 1) for sintering from PA12 powders with SLS process. One of them consists of a repeating unit cell with face centered cubic (FCC) structure and the other one consists of a similar unit cell but includes vertical columns (FCC-z). The lattice block sample consisting of $8 \times 8 \times 8$ unit cells are fabricated using a SLS machine (Farsoon High Tech, FS 251) from PA12 powder (ALM PA650) with a powder bed temperature of $170{ }^{\circ} \mathrm{C}$ using $0.100 \mathrm{~mm}$ layers and 0.25 $\mathrm{mm}$ scan spacing. In SLS process, the reuse of the supporting powder is recommended to reduce the purchase cost of the powder and minimise waste. The refresh rate defined as the percentage of the reused material is taken as $70 \%$.

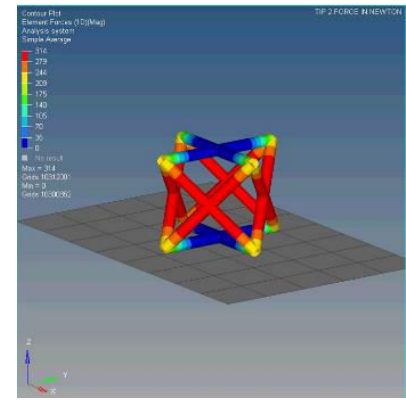

(a)

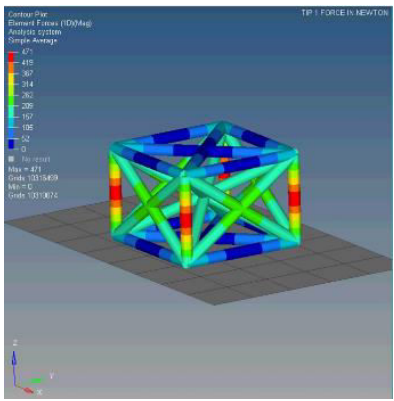

(b)

Fig. 1. The structure of the unit cell topologies (a) FCC unit cell (b) FCC unit cell with vertical columns (FCC-z).

The morhology of the powders are examined by using scanning electron microscope (SEM, Jeol 6060).

The thermal properties of the powders are analysed by using Differential Scanning Calorimeter (DSC, Perkin Elmer, DSC4000). The DSC analysis is applied to both virgin and reused powders and carried out in two stages. The powders are heated from 0 to $210^{\circ} \mathrm{C}$ at a heating rate of $10{ }^{\circ} \mathrm{C} / \mathrm{min}$, then they are cooled to $0^{\circ} \mathrm{C}$ at a cooling rate of $10{ }^{\circ} \mathrm{C} / \mathrm{min}$. The melting temperatures $\left(\mathrm{T}_{\mathrm{m}}\right)$ and crystallization temperatures $\left(\mathrm{T}_{\mathrm{c}}\right)$ are determined from the DSC-thermograms.

The compression test is realized on Autograph AG-IS $100 \mathrm{kN}$ Shimadzu Universal Testing Machine. SLS manufactured lattice structures are tested at a cross-head speed of 5 $\mathrm{mm} / \mathrm{min}$. The fracture mechanism of the lattice structure is investigated by performing a 
series of microstructural study using SEM, on different failed struts, after the compression test.

\section{Results and discussion}

The powder properties are important for a successful processing during SLS. The powder should have an appropriate particle size and morphology for a good flowability, deposition, sinterability and surface quality of the parts. The SEM images of the PA12 powder are given in Figure 2. The powders show a potato shaped morphology being typical for the powders produced by precipitation process [3]. The particle size of the powder for a good sintering ability is generally around 45-90 $\mu \mathrm{m}$ [1]. The particle size of the PA12 powder used in this study lies approximately between $30-100 \mu \mathrm{m}$.

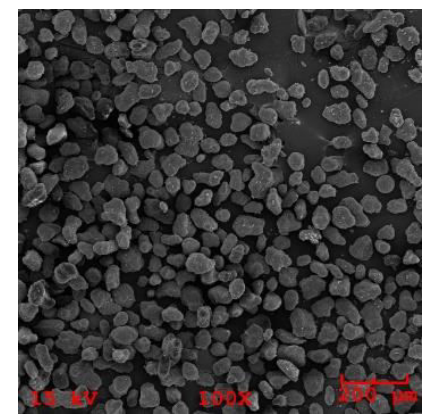

(a)

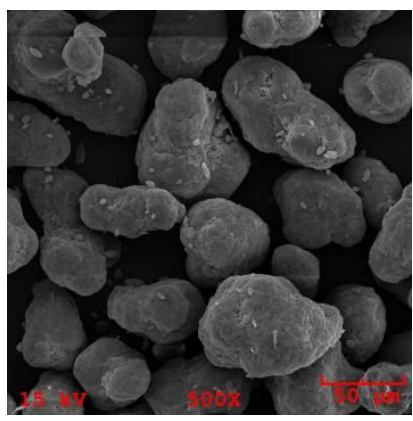

(b)

Fig. 2. The morhology of the virgin PA12 taken by SEM, at different magnifications.

The other important property for determining the process parameter for SLS is the thermal behaviour of the polymer. The difference between the melting and crystallization temperatures gives the operating temperature (processing) window for SLS [4]. The operating temperature window has to be as wide as possible for preventing part warpage by slow crystallization [2]. The DSC thermogram of the virgin PA12 is given in Figure 3.

The operating temperature window is determined as $24.3{ }^{\circ} \mathrm{C}$ from the 1 st heating and cooling curve of the DSC thermogram given in Figure 3. Generally, the powder bed temperature is kept $2-4{ }^{\circ} \mathrm{C}$ below the melting temperature. The large difference between the melting and crystallization peaks is an indication for a slow crystallization. Thus, the powders will remain longer in a liquid state during the cooling process and prevent the accumulation of residual stresses which will cause part distortion. However, aging of the powders is caused by exposure time at temperature close to the melting point.

Figure 4 gives the comparison of the 1st melting curves of the virgin und reused PA12 powders. The main melting temperature of the used powder is almost the same as of the virgin powder and is at $\sim 185^{\circ} \mathrm{C}$. However, the melting curve of the used powder became broader with a shoulder close to the main curve at a higher temperature. Studies related to the morhology of PA12 state the melting point of $\gamma$-type of PA12 between $172-185^{\circ} \mathrm{C}$ and mostly near to $179^{\circ} \mathrm{C}$ [5]. The melting temperature of the $\alpha$-type of PA12 is reported as approximately $173^{\circ} \mathrm{C}$. As demonstrated in many published data, the more stable $\gamma$-form of PA12 is the most observed crystal structure under the processing condition. Thus, the slow cooling rate during the production would result in more stable and larger crystals of $\gamma$-PA12 with higher melting temperature. The broad melting curve of the used PA12 powder is attributed to the crystallite size distribution. Generally, PA12 is produced by condensation reaction of an amine and an acid group. Therefore, an increase of the molecular weight by post condensation reaction, an increase of chain mobility and 
crystallization may cause the broad peak and shoulder at higher temperature due to keeping the powders near the melting temperature during the SLS processes of PA12 powders [6]. All these effects should be considered during processing and reusing of powders.

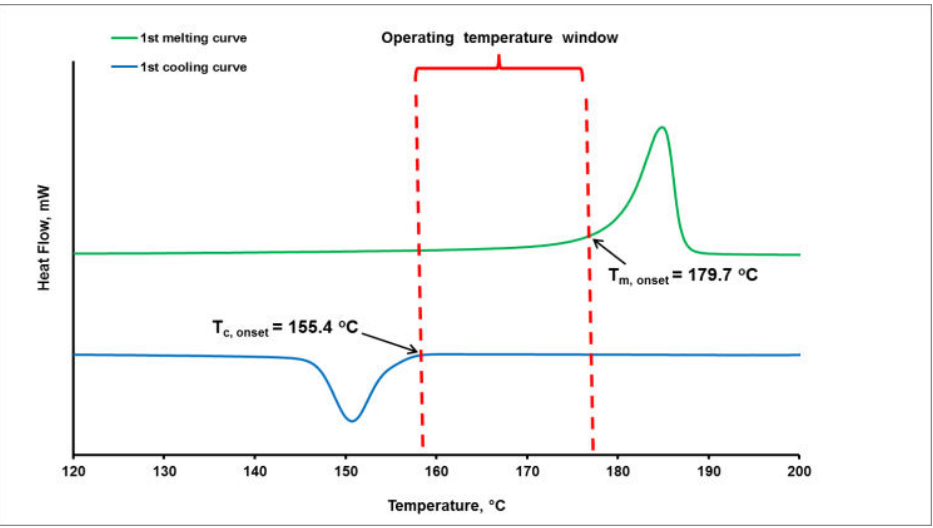

Fig. 3. The DSC thermogram of the virgin PA12.

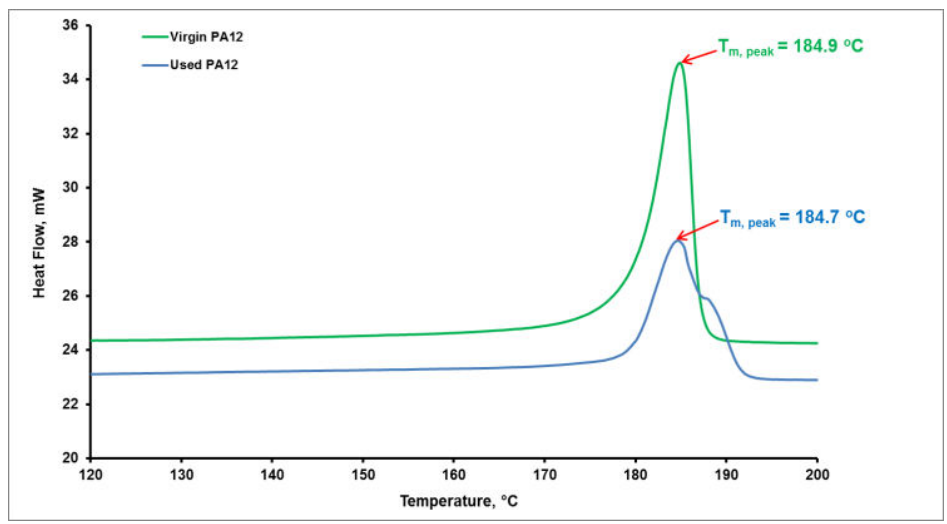

Fig. 4. The comparison of the 1st melting curves of the virgin und reused PA12 powders.

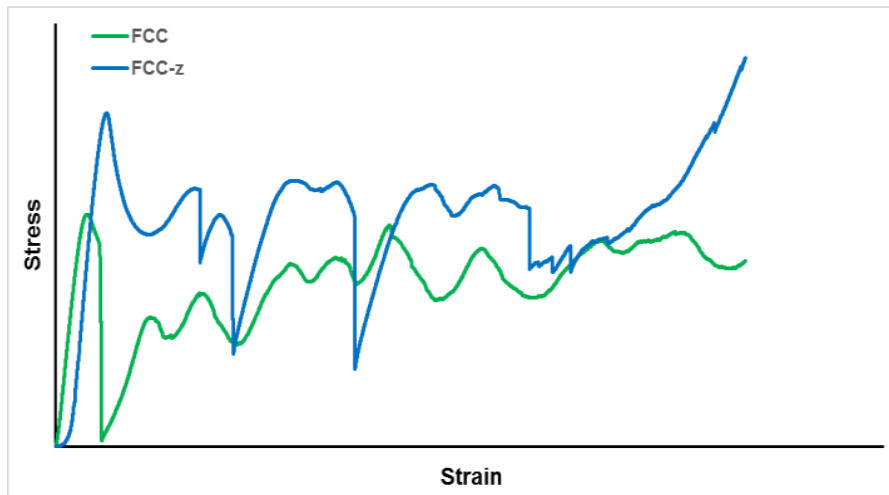

Fig. 5: The stress-strain curve of the lattice structures obtained during compression test. 


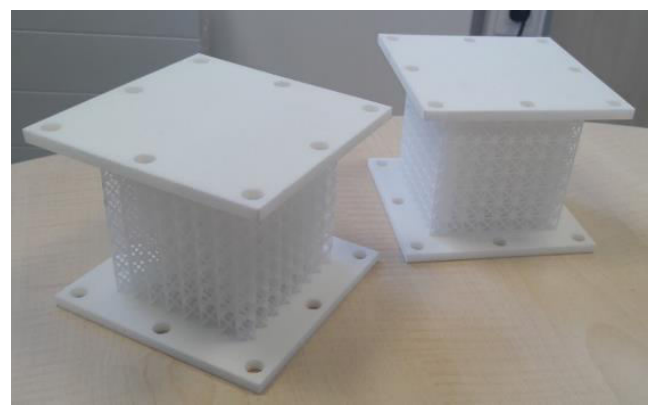

(a)

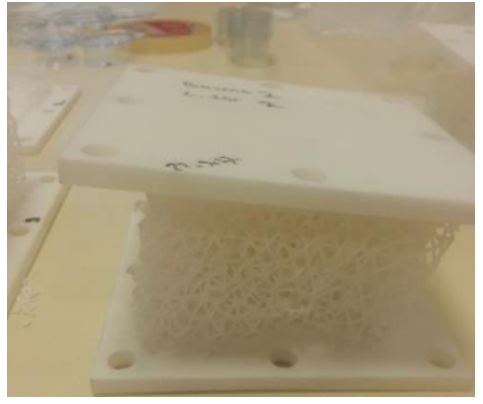

(b)

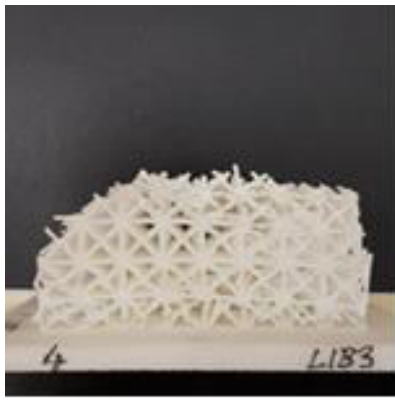

(c)

Fig. 6: Both lattice structures produced by SLS (a) before compression test, (b) FCC and (c) FCC-z after compression test.

The mechanical properties of semicrystalline polymers are a function of the amount and morphology of the crystalline regions. The crystalline region is responsible for the strength, whereas the amorphous region provides ductility by allowing the polymer to yield without breaking.

In this study the failure behaviour at different struts with different microstructural appearance is examined by SEM after dynamic compression test of the lattice structures in order to have an insight on the effect of the processing orientation, heat supply and reused powder. Both lattice structures with FFC and FFC-z unit cell topologies show firstly layerby-layer collapses which finally result with a shear fracture (Figure 5 and 6).

The stress type and distribution on the lattice structure under compression load are anizotropic because of the unit cell topologies and the anizotropic processing condition. Therefore, different kinds of fracture appearances are detected at different regions for the fractured struts.

PA12 is a semicrystalline polymer and has a highly heterogenous microstructure due to containing both amorphous and crystalline phases. A crystal lamella is connected by amorphous regions which contain non-entangled chains, dangling chain ends and/or loops and more or less taut tie-molecules [7]. A lamella will be deformed in shear or in tension or stack rotation depending on the relative orientation of a lamellar bundle with respect to the principal stress direction. Stress relaxation may occur through cavitation within the amorphous region or through crystal plastic deformation. Finally, this strong concentrated forces on the crystal lamellae with highly extended tie molecules will result with slipping on preferred lattice plane and/or crystal breakup. This mixed fracture behaviour is shown in Figure $7 \mathrm{a}$ where the shear bands and the crystalline regions are clearly visible. 


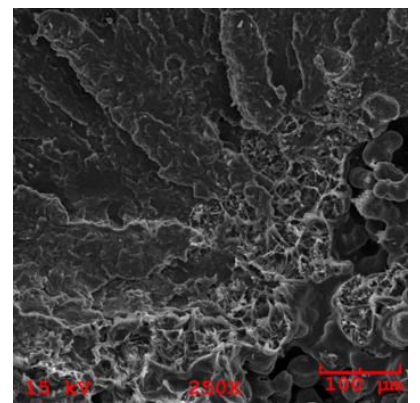

(a)

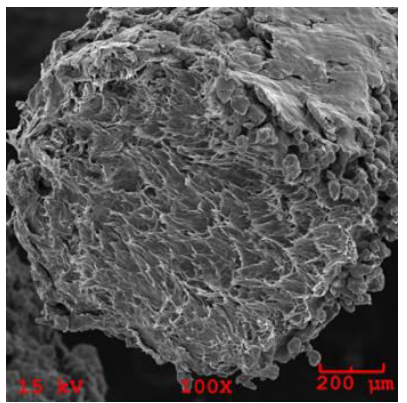

(b)

Fig. 7: Different fracture microstructures at different areas of failed struts.

Another fracture mechanism frequently seen in thermoplastic polymers is crazing [7, 8]. Crazing associated with fibrillated structure occurs at very localized plastic deformation areas (Figure 7b). Crazes start by formation of small and interconnected microvoids. These interconnection between the microvoids elongate with increasing of the applied stress and finally break with a fibrillated structure appearance. Crazes are sign of fracture toughness because the abillity of absorbing fracture energy before cracking.

Figure $8 \mathrm{a}$ illustrates a fracture surface at the junction point of diagonal struts. A lot of non-sintered powders are visible (Figure $8 \mathrm{a}$ and $\mathrm{b}$ ). Also the weak bonding of the individual sintering layers on the diagonal struts is recognized, which are the result of layer-by-layer processing /sintering (Figure 8a and c). The SLS is a process, in which the parts produced directly from 3D CAD models by building them in layers. After the contour and bulk of a layer is - optimally - fully sintered to the underlying layer, the whole powder bed is lowered by the defined step size $(40-200 \mu \mathrm{m})$ and a new non-sintered powder layer is added from the reservoir by a doctor blade or roller. Therefore, one of the major issues in SLS processing is the anisotropic mechanical properties of the laser sintered parts according to their build position which is the result of the layer-by-layer processing nature. Powders with an appropriate particle size and morphology for a good spreading in the built area (flowability), processing ability are the first essential features to minimize the gaps/voids/ pores in the laser sintered parts [1]. Ideal powder should have high sphericity for a good flowability, processability $[9,2]$. However, availability of polymers in powder form with high sphericity for laser sintering is the main problem. They are not produced directly in powder form, rather indirectly by co-extrusion processes, precipitation process or cryogenic milling. Generally, flowability agents like silica are usually added which could also act as defects (Figure 8d).

The other main cause for non-sintered powders is porosity in the microstructure which gives too less local heat supply. It leads to non-predicable, low fatigue strength and part lifetime. Accurate sensing and control of local powder bed temperature, laser power are the main precautions to reduce these undesirable phenomena.

Figure 9 shows a fracture surface with a heterogenous microstructure of another area of the lattice structure. Very large pores are visible at the edge of the struts probably due to the same reason as mentioned before. Here the main problem is the insufficient heat supply for fully melting of the powder and sintering. In SLS, polymers do not consolidate via solid state sintering because of the insufficient time for diffusion. In contrast, they consolidate by liquid phase sintering. Therefore, sufficient heat should be supplied for fully melting of the powders. In case of inadequate heating, only the shell of the powder will melt, whereas the core will remain solid and only the molten shell of the polymer powder will form necks between the neighbour powders (Figure 9c). In Figure 9d, another microstructural 
appearance of these heterogenous phenomena is given, which is also a consequence of insufficient heat supply.

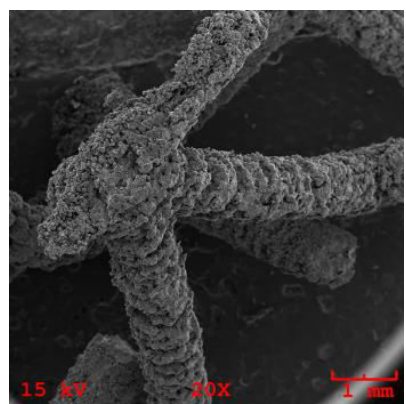

(a)

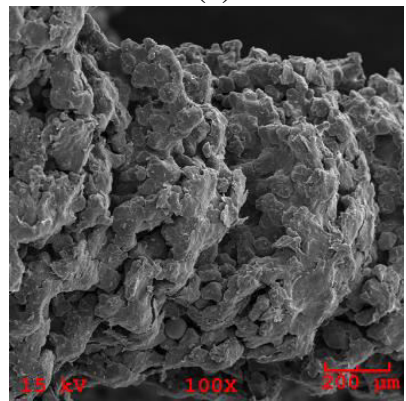

(c)

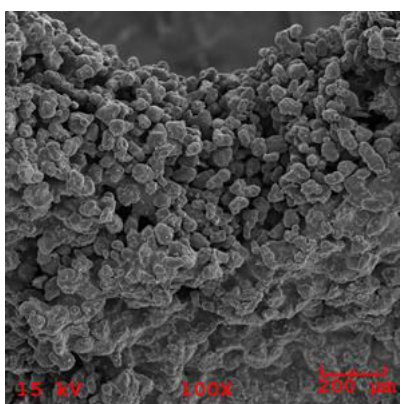

(b)

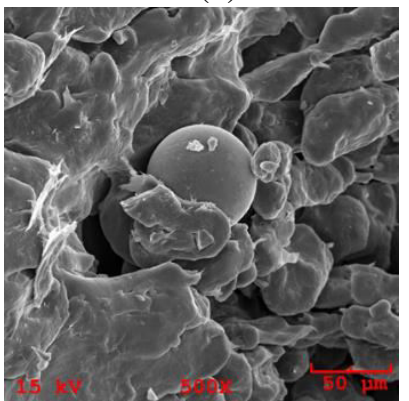

(d)

Fig. 8: Fracture surface at the junction point of diagonal struts.

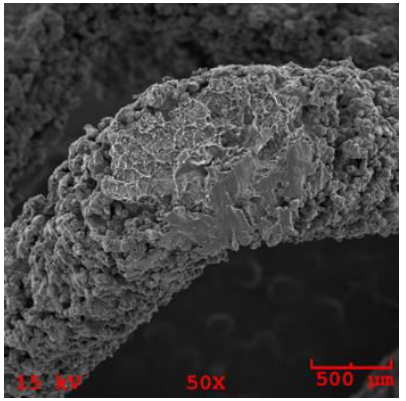

(a)

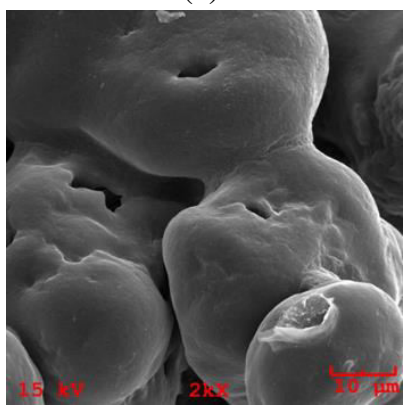

(c)

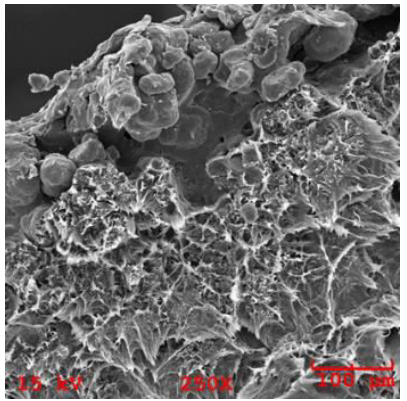

(b)

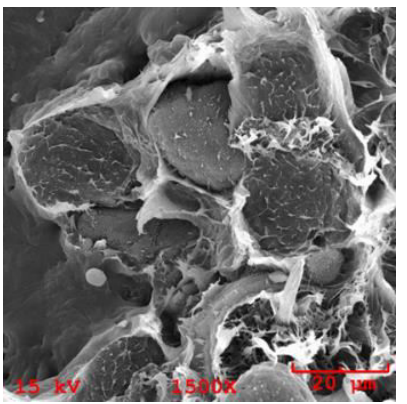

(d)

Fig. 9: Fracture surface of another area of the lattice structure 


\section{Conclusion}

In this study, it is aimed to obtain insight about the fracture behaviour of a lattice structure with macro-porosity produced by SLS. A series of microstructural investigations on different fracture surfaces is performed to correlate fracture microstructures and the processing condition.

The stress type and distribution on the lattice structure under compression load are anizotropic because of the unit cell topologies and the anisotropic processing condition. This is why different fracture appearances are observed on different failed struts of the lattice structure.

\section{Acknowledgements}

The authors acknowledge the financial support of Eurostars E!11261 slsPEEK4smal-series project in the frame of the EUREKA initiative of the European Union and the national funding agencies in Turkey (TUBITAK) and Austria (FFG).

\section{References}

1. R. D. Goodridge, C. J. Tuck, R. J. M. Hague, Progress in Materials Science, 57(2), 229-267, 2012.

2. S. Dupin, O. Lame, C. Barres, J.-Y. Charmeau, European Polymer Journal, 48, 1611$1621,2012$.

3. M. Schmid , K. Wegener, Procedia Engineering, 149, 457 - 464, 2016.

4. B. Fulcher, D. K. Leigh, The Twenty-Third Annual International Solid Freeform Fabrication (SFF) Symposium - An Additive Manufacturing Conference, The University of Texas in Austin, August 6-8, 2011.

5. H. Zarringhalam, N. Hopkinson, N. F. Kamperman, J. J. de Vlieger, Materials Science and Engineering A, 435-436, 172-180, 2006.

6. L. Verbelen, S. Dadbakhsh, M. Van den Eynde, J.-P. Kruth, B. Goderis, P. Van Puyvelde, European Polymer Journal, 75, 163-174, 2016.

7. H. H. Kausch, R. Gensler, C. Grein, C. J. G. Plummer, P. Scaramuzzino, Journal of Macromolecular Science, Part B Physics, 38, 803-815, 1999.

8. W. D. Callister, D. G. Rethwisch, John Wiley \& Sons Inc., NY, 2007.

9. D. Drummer, D. Rietzel, F. Kuhnlein, Physics Procedia, 5, 533-542, 2010. 